\title{
Institucionalidad electoral y derechos políticos de las mujeres en México
}

\section{María del Pilar Hernández*}

\section{Sumario:}

I. Consideraciones preliminares

II. Un marco clave: institucionalismo electoral; un concepto imprescindible: derechos políticos

III. Reconocimiento normativo de los derechos de las mujeres y partidos políticos

IV. ¿Y los partidos políticos?

V. Tutela jurisdiccional efectiva de los derechos políticos de las mujeres: la jurisdicción federal

VI. Conclusiones

VII. Fuentes de consulta

* Investigadora en el Instituto de Investigaciones Jurídicas de la UNAM.

Recibido: 20 de febrero de 2012 Aceptado: 14 de diciembre de 2012 


\section{Resumen}

El signo distintivo del moderno derecho constitucional es su impronta jurisprudencial, así, el derecho es, como sucede en el derecho anglosajón, lo que los jueces dicen que es. Al impulso de los nuevos vientos se realiza el análisis institucional, inclusivo y expansivo, de la tutela de los derechos subjetivos públicos por parte de las mujeres. El acceso a la jurisdicción constitucional vía el juicio para la protección de los derechos políticos electorales de los ciudadanos, ha hecho posible, en la visión "garantista-ferrajoliana” de la Sala Superior del Tribunal Electoral del Poder Judicial de la Federación, el acceso efectivo a un $40 \%$ de cargos de representación popular a las mujeres, con una fórmula que elimina la eventual elusión electoral.

\section{Abstract}

The distinctive feature of modern constitutional law is its jurisprudential imprint; thus, law is, as it happens in the Anglo-Saxon context, what Judges say it is. Driven by the force of the new winds, an institutional, inclusive and extensive analysis is performed concerning the protection of the subjective public rights of women. The article explains how the constitutional jurisdiction for the protection of the political-electoral rights of the citizens has made possible, according to the "ferrajolian" view of the Superior Chamber of the Federal Electoral Court, the effective access of women to forty percent of the elected offices through a formula that eliminates eventual electoral exclusion.

Palabras clave: derecho políticos, equidad de género, democracia sustantiva, acceso a la justicia.

Descriptors: political rights, gender equality, substantial democracy, access to justice. 


\section{Consideraciones preliminares}

El ejercicio de los derechos político-electorales de hombres y mujeres en la región latinoamericana, es un tema que aún no termina, su naturaleza multifactorial y multidimensional presenta avances y regresiones que van más allá de los esfuerzos por generar, primero, mecanismos que hagan posible la igualdad progresiva en la diversidad humana que históricamente nos ha signado y, segundo, la visibilización y resignificación de las mujeres en el acceso, goce, ejercicio y tutela jurisdiccional efectiva de derechos políticos electorales.

Decimos que el problema del acceso al pleno ejercicio de derechos políticos de las mujeres se agrava de cara a las viejas y nuevas condiciones que México presenta, entre otras: la situación de pobreza que conlleva a la atención prioritaria de necesidades básicas, los rezagos socioculturales, educativos y de salud de la población indígena femenina, su cada vez mayor inserción en una estructura laboral poco dignificante que absorbe y no abona en su ciudadanización, escasa atención a fenómenos de diversa naturaleza viejos pero con rostro de actualidad (desplazamiento interno por violencia generada por la delincuencia organizada, desastres naturales, obras públicas, inter alia) que inciden de manera específica en una eventual reivindicación de un estatuto político eficientemente participativo, entre otras. Nada ajeno a quienes desde el PNUD han focalizado el o los fenómenos en América Latina.

Es innegable que en el Estado mexicano en aras de su propia legitimidad y virtud la reivindicación de derechos políticos en la cabeza de diversos grupos de interés y de presión tuvo que transitar a la construcción de un "nuevo andamiaje institucional", que posibilitara la apertura democrática desde la misma institucionalidad, generando una especie de cambio atenuado de un partidismo monolítico y hegemónico, a un sistema multipartidista, la constitucionalización de los partidos políticos y la instauración de un sistema electoral mixto (mayoría relativa y representación proporcional) con predominante mayoritario: una arena de contienda plural ideológica y estructuralmente diferenciada a finales de los años setenta, puntualmente en 1977, que se dio en llamar la gran reforma política electoral "Reyes Heroles".

Después de 15 años se hace posible la emergencia de nuevas instituciones (un Instituto y un Tribunal electorales en la ola de los órganos 
autónomos) y reglas que oxigenaron aún más, virtud de los vientos de la transición democrática, espacios en que, paulatinamente, nuevos actores (mujeres, después jóvenes e indígenas, todos signados con un sistema de cuotas) adquirirán un rostro definido pero indefectiblemente condenados a ser cooptados por aquellos que buscaban legitimar la democracia mexicana y que hoy muestran los claros signos de una clase privilegiada que sólo observa una ley: la de hierro de las oligarquías.

Hablar entonces de institucionalismo político, específicamente electoral, hace necesaria la apelación a un contenido con contornos definidos, que permitan dimensionar, en prospectiva, lo que se avecina en México en las próximas elecciones de las que dos son de carácter federal (renovación de la titularidad del Ejecutivo Federal y senadores y diputados del Congreso General), 10 de carácter estadual y municipal, en total 12 elecciones concurrentes a celebrarse el primer domingo de julio.

\section{Un marco clave: institucionalismo electoral; un concepto imprescindible: derechos políticos}

El estudio de las instituciones como reglas formales e informales es de vital relevancia para estudiar los contextos latinoamericanos. Guillermo O'Donnell ${ }^{1}$ destaca la importancia de estudiar las reglas informales en los escenarios políticos de América Latina. Para O’Donnell las 'democracias' en América Latina son 'democracias delegativas', en donde los controles institucionales para vigilar el quehacer de los políticos son débiles. A contracorriente de la literatura politológica institucionalista de rational choice sobre América Latina, ${ }^{2}$ O’Donnell pone el acento en una perspectiva más de sociología política, en donde la institucionalidad se concibe también en marcos de reglas informales. En esta línea de O’Donnell, las investigaciones empíricas de Steven Levitsky y Leandro Wolfson se enfocan a estudiar las reglas tanto

1 O’Donnell, Guillermo, “Delegative Democracy”, Journal of Democracy, núm. 1, enero de 1994, pp. 55-69.

2 Munck, Gerardo L., 2004, "La política democrática en América Latina, contribuciones de una perspectiva institucional”, Política y Gobierno, núm. 2, II Semestre, pp. 315-346. 
formales como informales de la política. El trabajo clave de Levitsky y Wolfson ${ }^{3}$ es su estudio titulado Del sindicalismo al clientelismo: la transformación de los vínculos partido-sindicatos en el peronismo, 1983-1999 (2004). A estos trabajos se suma la obra de Gisela Zaremberg titulado Mujeres, votos y asistencia social en el México priista y la Argentina peronista. ${ }^{4}$ Estas dos últimas investigaciones son en parte respuesta a las investigaciones institucionalistas de la teoría de la elección racional que se inscriben en el estudio de la democracia en América Latina.

Confirmamos lo que O’Donnell expresara en el ya lejano 1996 a la luz de los elementos definitorios de las poliarquías, a saber:

1) Autoridades públicas electas.

2) Elecciones libres y limpias.

3) Sufragio universal.

4) Derecho a competir por cargos públicos.

5) Libertad de expresión.

6) Información alternativa.

7) Libertad de asociación.

México es una poliarquía institucionalizada informalmente, recobro las líneas de O’Donnell:

Los atributos del 1 al 4 nos dicen que un aspecto básico de la poliarquía es que las elecciones son incluyentes, limpias y competitivas. Del 5 al 7 se refieren a las libertades políticas y sociales mínimamente necesarias, no sólo durante los comicios sino también entre ellos, para que las elecciones sean limpias y competitivas. De acuerdo con estos criterios, algunos países de América Latina no son poliarquías en la actualidad: ... y México celebraron elecciones pero se vieron afectadas por serias irregularidades antes, durante y después de la votación.

Desde las reflexiones teóricas de la calidad de la democracia y construcción de ciudadanía, la situación en términos de avance sustantivo

3 Levitsky, Steven y Leandro Wolfson, "Del sindicalismo al clientelismo. La transformación de los vínculos partido-sindicatos en el peronismo, 1983-1999”, Desarrollo Económico, vol. 44, núm. 173, junio, pp. 3-32.

4 México, Flacso, 2009. 
de los derechos políticos electorales de las ciudadanas mexicanas y de las instituciones a cargo de rendir eficaces las normas ya instituidas, lejos están de asumir las esferas de los derechos, civiles, políticos, sociales y culturales, y transitar, así, de la democracia electoral a la democracia de ciudadanía.

Los elementos denotativos de la poliarquía sólo son concebibles a la luz de la categoría derechos políticos, que los denotamos como aquellos que posibilitan la participación de quienes tienen y rinden eficaz la calidad de ciudadanos en la conformación de la voluntad general del Estado, id est., los derechos a participar en el ejercicio del poder político a través del voto y el derecho a ser elegido (acotamiento sólo a éstos derechos que realiza Marshall) y que, inopinadamente, también comprende otras situaciones extensivamente tuteladas como lo son: ejercicio y goce del sufragio en elecciones directas (plebiscito, referéndum y/o revocación del mandato); libertades públicas de expresión y acceso a la información, asociación, reunión, manifestación en asuntos públicos, petición, derecho a ocupar cargos de designación y derecho a la tutela jurisdiccional efectiva (implicativa ésta del derecho al acceso a la justicia sin elementos de obstáculos procesales que lo impidan y mediante un recurso eficaz; obtener una sentencia de fondo debidamente fundada y motivada en un tiempo razonable; que la sentencia se cumpla - ejecutoriedad del fallo- todo ello mediante recursos eficaces).

En el marco del presente artículo, analizaremos el avance de los derechos políticos electorales de género a través de los partidos políticos, en tanto actores principales para el ejercicio de la representación política de las mujeres, la acción de los órganos electorales de la jurisdicción federal electoral para rendir eficaces esos derechos.

\section{Reconocimiento normativo de los derechos de las mujeres y partidos políticos}

El actual esquema de derechos políticos electorales de las mujeres se determina en tres tipos de normas, a saber: constitucionales, legales y reglamentarias.

A nivel constitucional, el catálogo de derechos se mantiene igual que en 1953, esto es, en 58 años normativamente el catálogo específicamente consagrado en los artículos 35 y 36 no ha sufrido cam- 
bios, sólo en lo que hace a la reivindicación del derecho a la igualdad formal entre hombres y mujeres (artículo 4o., párrafo primero), ${ }^{5}$ así como de los derechos de las mujeres indígenas a participar en la elección de sus representantes y a ser electas "en condiciones de equidad frente a los varones...” es lo encomiable (artículo 2o.). ${ }^{6}$

Formalmente el artículo 34 nos reconoce el estatus de ciudadanas y, en consecuencia, titulares de los derechos políticos reconocidos en el diverso 35, precepto que decimonónicamente mantiene, inexplicablemente y pese al sinnúmero de modificaciones que ha sufrido el texto constitucional, la expresión de prerrogativas. Se suman al anterior los prescritos en el artículo 36 en términos de obligaciones que, contrario sensu implican derechos, los siguientes:

1) Votar y ser votadas.

2) Ser nombradas para cualquier empleo o comisión, cumpliendo las calidades que establezcan las leyes.

3) De asociación política.

4) Tomar las armas en el Ejército o Guardia Nacional, para la defensa de la República y de sus instituciones.

5) Derecho de petición.

6) Inscripción en el catastro de la municipalidad y en el Registro Nacional de Ciudadanos.

7) Desempeñar los cargos concejiles del municipio donde se resida, las funciones electorales y las de jurado.

De todos estos derechos los más reivindicados y exigidos administrativa y jurisdiccionalmente ante los órganos electorales competentes son, en términos de cuotas y equidad, los dos primeros.

Ninguno de los dos preceptos indicados contiene expresión alguna en términos de equidad o paridad, aspecto éste que en las últimas reformas constitucionales de 2007, tampoco fueron reivindicadas en el artículo 41 que condensa, esencialmente, el fundamento de la regulación de los partidos políticos y de la autoridad administrativa electoral. Menos aún se hizo referencia al artículo 99 tratándose de la competencia del órgano jurisdiccional electoral. Ni qué decir de los intocados artículos 115 y 116 que prescriben las bases constituciona-

5 Diario Oficial de la Federación, 31 de diciembre de 1974.

${ }^{6}$ Diario Oficial de la Federación, 14 de enero de 2001. 
les de organización de los municipios y las entidades federativas. Sólo se hace alusión tangencial a la equidad en el artículo 134 en lo que hace a la responsabilidad de los servidores públicos (federales, estatales, municipales y del Distrito Federal) en caso de no observarla en la competencia de los partidos políticos.

Quizá ya no sea necesaria la referencia a equidad o, en su caso, paridad, virtud de las reformas constitucionales publicadas en el Diario Oficial de la Federación del 10 de junio de 2011, mediante las que se reconoce en el artículo 1o., que en México todas las personas gozarán de los derechos humanos reconocidos por la propia Constitución y los tratados internacionales de los que el Estado mexicano sea parte, así como de las garantías para su protección, y la obligación de "todas las autoridades, en su ámbito de competencia” de promover, proteger y garantizar los derechos humanos, expresión esta última que obliga, inopinadamente, a realizar control de convencionalidad que, dicho sea de paso, ya venía realizando la Sala Superior del Tribunal Electoral del Poder Judicial de la Federación, como lo veremos más adelante.

Las cuotas de género, sin lugar a dudas, son hasta el momento el mecanismo legal que permite asegurar un umbral mínimo de representatividad del género femenino, esencialmente en los órganos legislativos.

Quedaron atrás los primeros escarceos con las cuotas de género y la paridad que incidentalmente se consagraron en el otrora artículo 175 del Cofipe de $1993,{ }^{7}$ el reconocimiento expreso de $1996^{8}$ pasando por la memorable reforma de $2002^{9}$ que, personalmente, consideramos

7 En su numeral 3 del artículo 175 se establecía: "Los partidos políticos, promoverán en los términos que determinen sus documentos internos, una mayor participación de las mujeres en la vida política del país, a través de su postulación a cargos de elección popular".

${ }^{8}$ Fracción XXII, transitoria del artículo 5o. del Cofipe: "Los partidos políticos nacionales considerarán en sus estatutos que las candidaturas a diputados y senadores no excedan el 70 por ciento para un mismo género. Asimismo promoverán la mayor participación de las mujeres".

9 Artículo 175-A.- De la totalidad de las solicitudes de registro, tanto diputados como senadores que presenten los partidos políticos o las coaliciones ante el IFE, en ningún caso incluirán más del 70\% de candidatos propietarios de un mismo género.

Artículo 175-B.- De la lista de representación proporcional se integrarán por segmentos de tres candidaturas. En cada uno de los tres primeros segmentos de cada lista habrá una candidatura de género distinto. Lo anterior sin perjuicio de lo que señale la normatividad interna y el procedimiento de cada partido político. 
presentó una sola falencia: liberó las cuotas a los partidos políticos tratándose de candidaturas de mayoría relativa resultado de "procesos de elección mediante voto directo". Expresión abierta sin mecanismo o procedimiento claro que definiese tal elección.

A la sazón de las reformas constitucionales en materia electoral que se verificaron en 2007, ${ }^{10}$ en $2008^{11}$ se expide un nuevo Cofipe que se erige en el referente más actual de la legislación electoral, en materia de cuotas y equidad de género los aspectos relevantes y que se enderezan a las obligaciones de los partidos políticos son:

a) Deberán observar la igualdad de oportunidades y la equidad entre los hombres y mujeres para tener acceso a cargos de elección popular, incluidos en su declaración de principios y en sus órganos de dirigencia así como en el registro de candidatos (artículos 4o., in fine; 25.1, inciso $e$; 38.1, inciso $s$; 218.3).

b) Registrar candidatos a diputados y senadores por los principios de mayoría relativa y representación proporcional, en fórmulas compuestas por propietario y suplente, considerándose fórmulas y candidatos por separado, salvo para efectos de la votación (artículo 218).

c) Se eleva la cuota "al menos al cuarenta por ciento de candidatos propietarios de un mismo género, procurando la paridad" (artículo 219).

d) Las listas plurinominales deberán contener al menos, dos mujeres en cada segmento de cinco candidatos de manera alternada (artículo 220.1).

e) Se siguen exceptuando de la cuota de género "las candidaturas de mayoría relativa que sean resultado de un proceso de elección

Por su parte el artículo 175-C disponía una serie de medidas dirigidas a los partidos políticos con la finalidad de rendir eficaces las disposiciones de los dos preceptos precedentes, por lo que hecho el cierre de candidaturas el Consejo General del IFE podía requerir a un partido político o coalición para que en el plazo de 48 horas, contadas a partir de la notificación, rectificase la solicitud de registro, apercibiéndole que de no hacerlo procedía amonestación pública. En caso de reincidencia procedía la negativa del registro de las candidaturas; como hasta ahora ocurre, se exceptúan las candidaturas de mayoría relativa resultado de la elección mediante voto directo, esto es así bajo el principio de la conservación de los actos válidamente celebrados.

10 Diario Oficial de la Federación, del 13 de noviembre de 2007.

11 Diario Oficial de la Federación, del 14 de enero de 2008. 
democrático, conforme a los estatutos de cada partido" (artículo 219).

f) Se autoriza la sustitución de candidatos, las condiciones y plazos de procedencia (artículo 227).

g) Se prescribe como infracción el incumplimiento del principio de imparcialidad previsto en el artículo 134 de la Constitución federal, cuando la conducta afecte la equidad de la competencia de los partidos políticos, entre los aspirantes, precandidatos o candidatos durante los procesos electorales, haciendo imputables a las autoridades o servidores públicos de los Poderes de la Unión, entidades federativas, municipios, Distrito Federal u órganos autónomos (artículo 237).

h) De manera inédita se dispone en el artículo 78.1.a.V. que los partidos políticos deberán destinar el $2 \%$ de su financiamiento público anualmente para "capacitación, promoción y desarrollo de liderazgo político de mujeres”.

La puesta en marcha del nuevo porcentaje de cuotas tuvo lugar en las pasadas elecciones legislativas federales realizadas en 2009, a través de las cuales se eligieron a las diputadas y los diputados de la LXI Legislatura. Tratándose de los senadores y en lo que hace a las medidas prescritas para fortalecer el liderazgo de las mujeres habrán de observarse en las elecciones de 2012, lo cual hace por demás aventurada cualesquier evaluación.

Si bien, a la luz de la actual conformación de la Cámara de Diputados resultado de la aplicación de las medidas antes enunciadas, es posible advertir un pequeño avance en términos del aumento en el número de mujeres legisladoras, que no alcanza siquiera a cubrir el piso mínimo de $30 \%$ (que finalmente volvió a quedar en $27.6 \%$, en razón de la solicitud de licencia de legisladoras en favor de familiares u otros personajes de sus partidos - PRI, PRD, PVEM y PT $-{ }^{12}$ ) recomendado en el ámbito internacional; a lo anterior se suma que ninguno de los principales partidos políticos presenta en su grupo parlamentario

12 PRI: Ana María Rojas por Julián Nazar (su concuño y líder de la CNC); Carolina García por Alejandro del Mazo (hijo del ex gobernador, Alfredo del Mazo); PRD: Olga Luz Espinoza por Carlos Esquinca; PVEM: Mariana Ezeta por su hermano Carlos Alberto (ex consejero de la CIRT); Kattia Garza por Guillermo Cuevas (esposo); Laura Elena Ledezma por Maximino Fernández; PT: Anel Patricia Nava por Primitivo Ríos (líder de la colonia Tierra y Libertad, de Monterrey); Yulma Rocha por Catarino Mendoza. 
la cuota mínima de $40 \%$ de mujeres legisladoras, tal como se observa más adelante en este estudio. Sin embargo la cifra es de considerar ya que supera lo obtenido en la LIX Legislatura (2003-2006) y que fue de $27.6 \%$.

Por lo que hace al 2\% para fomentar la capacitación y liderazgo de las mujeres es de referir que a partir de 2008, el Instituto Federal Electoral ha realizado "puntualmente" su labor de fiscalización con la finalidad de evitar una nueva forma de elusión electoral que perjudica la inclusión de las mujeres y la plena consolidación de una ciudadanía de género, así mediante la aprobación del Reglamento para la Fiscalización de los Recursos de los Partidos Políticos Nacionales"13 y que de conformidad con su artículo Primero transitorio, entró en vigor el 1o. de enero de 2009, con excepción de las obligaciones relativas a la presentación de los informes trimestrales; el registro y comprobación de los gastos relacionados con el desarrollo de las actividades específicas a que se refiere el inciso $c$ del artículo 36, del Cofipe; la comprobación y registro de los gastos destinados a la capacitación, promoción y desarrollo del liderazgo político de las mujeres; así como la comprobación y registro de los ingresos y egresos relacionados con las precampañas, las cuales surtieron efectos a partir de su aprobación por el Consejo General del Instituto Federal Electoral.

No obstante la diligente actuación del IFE, tal como lo ha reconocido su actual presidente de 2008 a 2011, los partidos han gastado en ese rubro 224734020 pesos.

${ }_{13}$ Diario Oficial de la Federación del 8 de septiembre de 2008. 


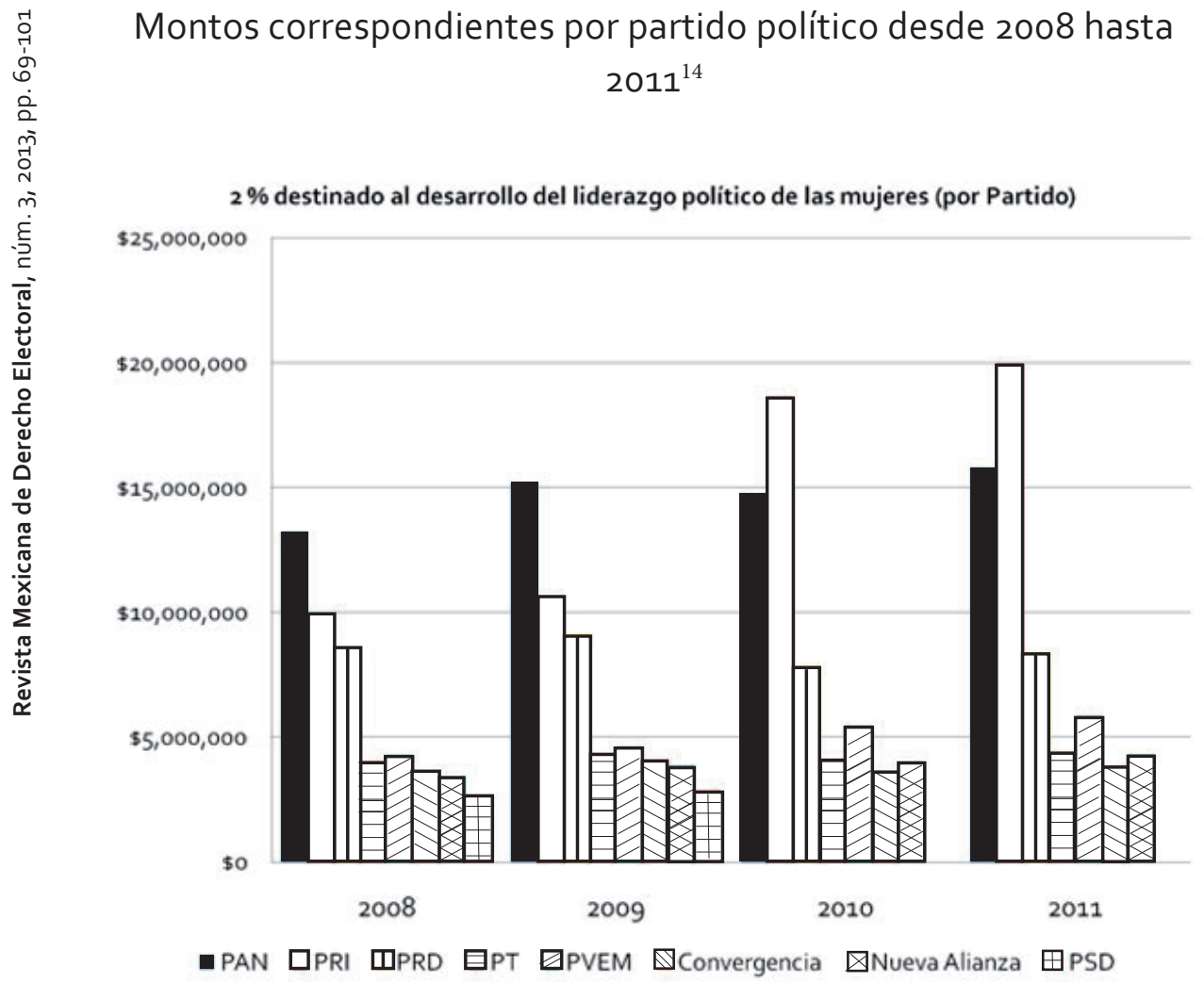

14 Género y Democracia, México, IFE, 2011, véase: http://genero.ife.org.mx/genero_ partidos.html. 


\section{Desglose por cantidades}

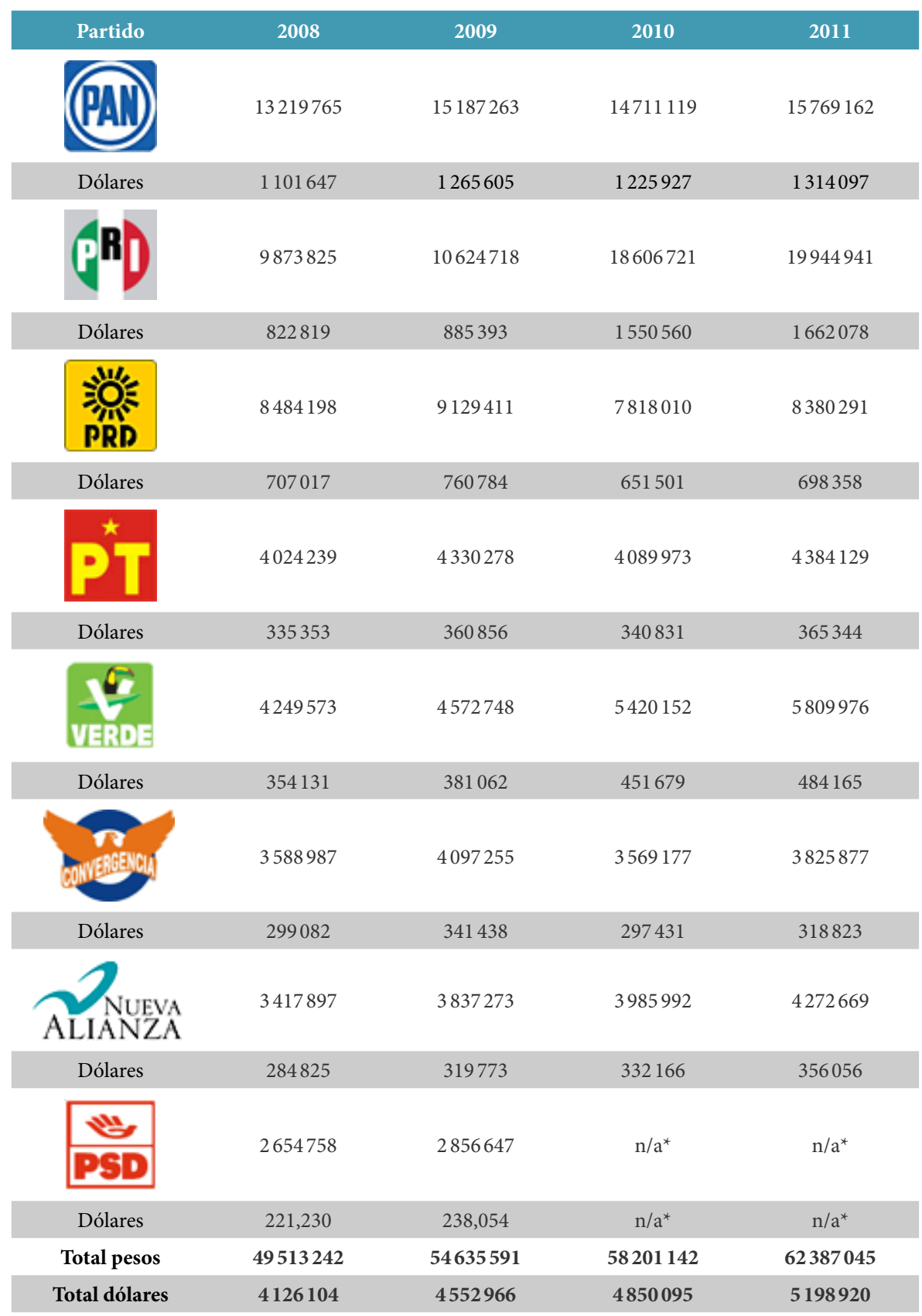

Nota: las cantidades están expresadas en pesos mexicanos en la primera fila de datos y en la segunda se expresan en dólares americanos, el tipo de cambio es de \$12 por dólar.

*No aplica debido a que el partido perdió el registro. 
En julio de 2011 el Consejo General del IFE aprobó las modificaciones al Reglamento de Fiscalización, ${ }^{15}$ en ellas se integran puntualizaciones en referencia al uso del $2 \%$ de gasto ordinario para la capacitación, promoción y desarrollo del liderazgo político de las mujeres. Las modificaciones definen a través de conceptos de la Perspectiva de Equidad de Género las actividades, los programas y contenidos, así como las precisiones y evidencias que los partidos políticos deben presentar al reportar los gastos.

En estricto sentido se determina que el 2\% del financiamiento anual deberá ser afectado puntualmente a la capacitación, promoción y desarrollo del liderazgo político de las mujeres con un enfoque de equidad (artículo 221), así como investigación, análisis, diagnóstico y estudios comparados, y divulgación y difusión (artículo 284).

Se determina que los partidos políticos, dentro de los 30 días siguientes a la aprobación del financiamiento público para actividades ordinarias permanentes por parte del Consejo General del IFE, deberán presentar un programa de gastos para el desarrollo de las actividades específicas y otros gastos (artículo 286).

Conforme al numeral 2 del propio artículo 286, se prescribe que los programas de gasto para la capacitación, promoción y desarrollo del liderazgo político de las mujeres deberán retomar los elementos siguientes:

a) Acciones afirmativas: medidas temporales cuyo fin es acelerar la participación en condiciones de igualdad de la mujer en el ámbito político, económico, social, cultural y civil, o en cualquier otro ámbito. El Comité contra todas las Formas de Discriminación contra la Mujer (CEDAW) en su "Recomendación General 25", considera la aplicación de estas medidas no como excepción a la regla de no discriminación, sino como parte de una estrategia necesaria para lograr la igualdad sustantiva de la mujer y el hombre en el goce de sus derechos humanos y libertades fundamentales.

b) Adelanto de las mujeres: disminución de las brechas de desigualdad entre mujeres y hombres a fin de garantizar el pleno reconocimiento, goce y ejercicio de sus derechos con base en la igualdad tanto sustantiva como política de Estado.

${ }^{15}$ Diario Oficial de la Federación del 7 de julio de 2011. 
c) Empoderamiento de las mujeres: es un proceso por medio del cual las mujeres transitan de cualquier situación de opresión, desigualdad, discriminación, explotación o exclusión a un estadio de conciencia autodeterminación y autonomía, el cual se manifiesta en el ejercicio del poder democrático que emana del goce pleno de sus derechos y libertades.

d) Igualdad sustantiva: supone la modificación de las circunstancias que impiden a las personas el ejercicio pleno de los derechos y el acceso a las oportunidades a través de medidas estructurales, legales o de política pública.

e) Liderazgo político de las mujeres: se refiere a las capacidades de las mujeres para influir en la esfera pública con pleno ejercicio de sus derechos en el ámbito político.

Por desarrollo del liderazgo político se debe entender la evolución progresiva de la condición de las mujeres para potenciar su liderazgo político en los espacios de toma de decisión.

Asimismo, por promoción del liderazgo político se debe entender el impulso de acciones afirmativas que permitan alcanzar el efectivo liderazgo político de las mujeres.

f) Perspectiva de género: permite visibilizar la asignación social diferenciada de roles y tareas en virtud del sexo; revela las diferencias en oportunidades y derechos que siguen a esta asignación; evidencia las relaciones de poder originadas en estas diferencias, y pregunta por los impactos diferenciados de las leyes y políticas públicas basadas en estas asignaciones, diferencias y relaciones de poder.

Por su parte el artículo 287, último párrafo, clarifica a los partidos políticos lo que habrán de entender por capacitación en tanto: el programa de enseñanza aprendizaje que los partidos políticos deben implementar para mejorar y ampliar los conocimientos, habilidades y aptitudes que fomenten los liderazgos políticos y el empoderamiento de las mujeres, a fin de lograr su inclusión en la toma de decisiones en condiciones de igualdad con los hombres. El diverso 288.1.b, puntualiza que la capacitación, promoción y el desarrollo del liderazgo político de las mujeres deberán contener información, valores, concepciones y actitudes orientadas a propiciar la igualdad de oportunidades para el desarrollo político, en el acceso al poder público y la participación en los procesos de toma de decisiones. Asimismo, deberán desarrollarse 
en el territorio que comprende los Estados Unidos Mexicanos, procurando beneficiar al mayor número de mujeres.

Se comprenden en el rubro de capacitación y formación para el liderazgo político de la mujer una serie de actividades que van de las conferencias, seminarios, entre otros, que favorezcan el desarrollo de conocimientos, habilidades y actitudes, en temas por demás diversos (artículo 293) que, desde nuestra óptica en nada abonan a la ciudadanización de género.

Para evitar la distracción de recursos, no se considerarán gastos programados aquellos de carácter operativos y servicios personales generales de las secretarías de la mujer de los propios partidos u órganos equivalentes cuando no se encuentren relacionados de manera directa y exclusiva con las actividades específicas y el correspondiente a la capacitación, promoción y el desarrollo del liderazgo político de las mujeres.

Esperaremos a que el nuevo Reglamento sea aplicado y el Consejo General del IFE rinda el correspondiente informe 2012 para verificar el cumplimiento del mismo.

\section{IV. ¿Y los partidos políticos?}

Conforme a las cifras que arroja la Lista Nominal de Electores a 2009, las mujeres en términos absolutos representamos de un total de 77.5 millones de ciudadanos el $51.8 \%$ de cara al $48.2^{16}$ de los hombres, sociológica y políticamente estamos subrepresentadas, no obstante en casi la misma proporción generamos el mayor porcentaje de votación que, en términos absolutos ascendió en 2009 a 34.1 millones de votantes de los cuales significamos 19 millones, y en términos de no voto de un total de 43.4 millones, 21 millones, a diferencia de los hombres que dejaron de emitir su sufragio en un número de 22.3 millones.

Conforme a la cohorte de edad y sexo se aprecia que la participación en las mujeres es siempre superior a la de los hombres desde los 18 años hasta el grupo 45-49.

${ }^{16}$ Instituto Federal Electoral, Estudio muestral de participación ciudadana en las elecciones 2009, véase: $w w w$.ife.org. $m x$. 
Cuantitativamente los partidos políticos nacionales arrojan los siguientes números de afiladas: ${ }^{17}$

\section{Afiliados a los partidos políticos porcentajes relativos mujeres/hombres}

\begin{tabular}{|l|c|c|c|}
\hline PARTIDO POLÍTICO & $\begin{array}{c}\text { TOTAL } \\
\text { AFILIADOS/AS } \\
\text { Términos absolutos } \\
\text { millones }\end{array}$ & $\begin{array}{c}\text { MUJERES } \\
\text { AFILIADAS } \\
\text { Términos } \\
\text { relativos }\end{array}$ & $\begin{array}{c}\text { HOMBRES } \\
\text { AFILIADOS } \\
\text { Términos relativos }\end{array}$ \\
\hline Convergencia & 136756 & $5674 \%$ & $43.26 \%$ \\
\hline $\begin{array}{l}\text { Partido Acción Nacional } \\
\text { (PAN) }\end{array}$ & 1314901 & $47 \%$ & $53 \%$ \\
\hline $\begin{array}{l}\text { Partido Nueva Alianza } \\
\text { (Panal) }\end{array}$ & 13000 & SIN DATOS & SIN DATOS \\
\hline $\begin{array}{l}\text { Partido Verde Ecologísta } \\
\text { (PVEM) }\end{array}$ & 359901 & $18.18 \%$ & $81.82 \%$ \\
\hline $\begin{array}{l}\text { Partido de la Revolución } \\
\text { Democrática (PRD) }\end{array}$ & 1795851 & $64 \%$ & $36 \%$ \\
\hline $\begin{array}{l}\text { Partido Revolucionario } \\
\text { Institucional (PRI) }\end{array}$ & sin datos & sin datos & sin datos \\
\hline Partido del Trabajo (PT) & sin datos & sin datos \\
\hline
\end{tabular}

17 Cifras consultadas en el sitio de GEPALL: Género y Partidos Políticos en América Latina, Banco Interamericano de Desarrollo, véase: http://www6.iadb.org/Research/ Geppal/tabsdataParty.cfm?language=Spanish\&country=MEX\&parties=57\& category=1ぬ pagref $=1$. 
Inclusión de mujeres en cargos de dirigencia partidaria. Máximo órgano ejecutivo

\begin{tabular}{|l|c|}
\hline \multicolumn{1}{|c|}{ PARTIDO POLÍTICO } & TÉRMINOS RELATIVOS \\
\hline Convergencia & $14.81 \%$ \\
\hline Partido Acción Nacional (PAN) & $11.76 \%$ \\
\hline Partido Nueva Alianza (PANAL) & $11.76 \%$ \\
\hline Partido Verde Ecologísta (PVEM) & $11.00 \%$ \\
\hline Partido de la Revolución Democrática (PRD) & $50 \%$ \\
\hline Partido Revolucionario Institucional (PRI) & $22.22 \%$ \\
\hline Partido del Trabajo (PT) & SIN DATOS \\
\hline
\end{tabular}

Como es de apreciarse dos partidos no cuentan con datos, uno de ellos, el Partido Revolucionario Institucional en tanto segunda fuerza electoral, no ofrece en su sitio ni en el Instituto Federal Electoral cifras del total de afiliadas(os).

De cara a las normas antes transcritas de orden que de origen dejan clara la intención de los partidos políticos en eludir, una vez más, las normas que les obligan a las cuotas de género:

1) A través de la excepción a las candidaturas de mayoría relativa que sean resultado de un proceso de selección democrático, de acuerdo con los estatutos de cada partido.

2) Mediante la integración de fórmulas ya sea de mayoría relativa o de representación proporcional mujer-hombre que indefectiblemente habrán de satisfacer lo prescrito en los artículos 218 y 220.1, respectivamente, pero que por el mismo esquema de dominación y sobreposición partidaria en las elecciones internas o primarias exista el acuerdo de la solicitud de licencia a favor de los suplentes hombres.

Históricamente cada tres años las bancadas hacen movimientos para resarcir los lugares previstos para hombres y que tuvieron que dárselos de inicio a una mujer para cumplir con la cuota legal de género. El asunto conocido en México como "El caso Juanitas" resuelto por el Tribunal Electoral del Poder Judicial de la Federación a través del juicio para la protección de los derechos políticos electorales del ciudadano(a) en el expediente identificado como SUP-JDC-3049 y su acumulado SUP-JDC-3048/2009 y que desarrollaremos líneas abajo. 
Caso diverso es aquél de la observancia del principio de alternancia en la integración de las fórmulas de representación proporcional en segmentos de cinco, expediente identificado como SUP-JDC 461/2009.

3) Si bien las elecciones primarias pueden democratizar la selección de candidatos, este efecto puede ir en sentido contrario al efecto de las cuotas de género si, por ejemplo, los candidatos masculinos cuentan con más recursos de campaña, o bien con un mayor reconocimiento por parte del electorado. Es por ello que existe una tensión natural entre quienes buscan una mayor equidad de género en las candidaturas y quienes buscan una mayor democratización interna de los partidos.

4) El cumplimiento de las cuotas y asignadas a mujeres que no gozan de arraigo o liderazgo en sus respectivas circunscripciones, de cara al género masculino que sí lo tienen. Estamos más que convencidas que los dirigentes partidarios diseñan su propia geografía electoral que les permite, antes que perder un escaño o curul, sacrificar a sus mujeres militantes.

5) En razón de su menor militancia y participación política las mujeres no cuentan con el mismo capital político que los hombres de sus propios partidos, que escatiman incluso los propios recursos asignados para campañas en aras, salvo que, eventualmente, haya una mujer con mayores posibilidades.

Es evidente que las prácticas elusivas de los entes partidarios no tienen límites, en prospectiva a las elecciones de 2012 y ante el déficit de credibilidad existe alta probabilidad que radicalicen sus estrategias desde las elecciones primarias de sus candidatos.

\section{Tutela jurisdiccional efectiva de los derechos políticos de las mujeres: la jurisdicción federal}

\section{Sentencias relevantes}

En 2002 el tribunal pleno de la Suprema Corte de Justicia de la Nación conoció la acción de inconstitucionalidad identificada bajo los número 2/2002 promovida por el Partido Acción Nacional en contra 
del "Decreto número 176 publicado en el Periódico Oficial del Estado de Coahuila el día dieciséis de noviembre del año en curso mediante el cual se crea la Ley de Instituciones Políticas y Procedimientos Electorales para el Estado de Coahuila de Zaragoza, impugnándose en lo específico por esta acción de inconstitucionalidad los artículos 20, 21, 25, fracción I, 26, fracciones VII y VIII, 103, fracción IV, 107, 108, 109, $110,111,112,113,192,222,239$ y $240 "$.

El partido argumentaba la inconstitucionalidad de una cuota de género tan elevada (70\%) toda vez que se disponía que los partidos políticos en representación proporcional y mayoría relativa impulsarían la equidad de género, por lo que el registro de candidatos tanto para propietarios como para suplentes opera con la referida cuota.

La resolución resultó por demás polémica y dividida, los argumentos en contra tendían a determinar que la Ley de Instituciones Políticas y Procedimientos Electorales de Coahuila impone una cuota de género y que ésta carece de apoyo constitucional ya que el artículo 40. establece la igualdad ante la ley de mujeres y hombres y que, por tanto, “... le está vedado al legislador plasmar cuotas de género, pues viola el derecho de igualdad político electoral de los ciudadanos de votar y ser votados...."

Sin embargo, la opinión a favor resultó apoyada por la mayoría de los ministros, argumentando que la norma estudiada no está destinada a los ciudadanos sino a los partidos políticos, y que estas instituciones, al ser el mecanismo de acceso al poder de los ciudadanos, están sometidas a las formas específicas de intervención que la ley señale.

Sin lugar a dudas memorable resolución.

Ahora una lamentable regresión.

En 2009, nuevamente el pleno de la Corte conoce de acciones de inconstitucionalidad acumuladas en materia de cuotas de género consagradas en el Código Electoral de la entidad federativa Veracruz Llave (7/2009, 8/2009 y 9/2009) promovidas por Convergencia, Partido Político Nacional, Partido Acción Nacional y Partido de la Revolución Democrática y de las cuales resolvió que el porcentaje de candidaturas que se destinan para las mujeres en los estados de la República, y que se lleva a cabo mediante las cuotas de género, puede ser menor al $40 \%$ que se exige a nivel federal.

La decisión se tomó con el voto en contra de las dos ministras que tiene la Corte. 
En una votación dividida, la mayoría de ministros concluyó que la Constitución no garantiza ni fija cuotas de género y que los estados son libres de fijar el porcentaje.

Los estados, resolvieron, tampoco están obligados a seguir el modelo del Código Federal de Instituciones y Procedimientos Electorales (Cofipe), en donde se obliga a partidos a garantizar que $40 \%$ de sus candidaturas a diputados y senadores serán de un mismo género, "procurando llegar a la paridad".

La Corte se pronunció sobre este tema al revisar un par de juicios de acciones de inconstitucionalidad que promovieron los partidos Acción Nacional y Convergencia en contra de las recientes reformas electorales en Veracruz, donde, entre otros temas, sólo se reservó a mujeres $30 \%$ de candidaturas locales a cargos de elección popular.

Como encargada de los juicios, la ministra Margarita Luna Ramos, pidió a sus compañeros que se declarara inconstitucional este punto, porque llegó a la conclusión de que esta medida es discriminatoria e inequitativa.

Pero su propuesta no tuvo éxito. A ella sólo se sumaron el ministro Juan Silva Meza, y la ministra Olga Sánchez Cordero, quien les dijo a sus compañeros que "una real equidad en materia de participación de géneros en la vida política de una sociedad y un Estado democrático, debe conseguirse procurando que tanto el hombre como la mujer cuenten con iguales oportunidades para acceder a cargos de elección popular".

La mayoría, integrada por seis ministros — debido a la ausencia de dos de los integrantes del pleno-, no compartió sus argumentos y validó el sistema de cuotas de Veracruz, por considerarlo razonable. En especial porque, antes de las reformas, no había el sistema de cuotas.

A manera de justificación, el entonces presidente de la Corte, Guillermo Ortiz Mayagoitia, dijo que el sentido de su voto hubiera sido el mismo si se hubiera fijado como fórmula de cuota de género un 50 $50,60-40$ y hasta un 75-25.

El ministro Genaro Góngora dijo que "la Constitución exige que el legislador repare las desigualdades, pero deja en sus manos el diseño de mecanismos, sin que haya fundamento para imponer a estados, la solución adoptada a nivel central".

Cosas veredes que no creeredes

Más allá de aquellas acciones de inconstitucionalidad o amparos en revisión que por imperativo del artículo 105, fracciones II y III de la 
Constitución federalllega a conocer en materia política el tribunal pleno de la Suprema Corte de Justicia de la Nación, los asuntos más paradigmáticos han sido conocidos por la Sala Superior del Tribunal Electoral del Poder Judicial de la Federación multicitada en el presente documento vía el medio de impugnación ad hoc como lo es el juicio para la protección de los derechos políticos electorales del ciudadano (JDC).

Sólo deseo dejar anotados dos casos que, desde mi óptica resultan modélicos en materia de protección de derechos, a saber:

- SUP-JDC 461/2009 alternancia de genero SX-JDC 159/2009, el caso específico analizado es el juicio para la protección de los derechos político-electorales del ciudadano (JDC), interpuesto por la ciudadana Mary Telma Guajardo Villarreal, quien se inconforma por el lugar que le fue asignado en la lista de candidatos a diputados federales por el principio de representación proporcional (artículo 120.1 del Cofipe) en la Segunda Circunscripción Electoral Plurinominal, integración avalada por el Segundo Pleno del Consejo Nacional del Partido de la Revolución Democrática (PRD), y luego ratificada por la Comisión Nacional de Garantías del mismo partido. Al no prosperar su pretensión en las instancias internas, Guajardo Villarreal interpuso juicio ante el Tribunal Electoral del Poder Judicial de la Federación (TEPJF). En él argumentó que el lugar que le había sido asignado (el cuarto) no correspondía con los criterios de equidad de género establecidos por el Cofipe a ese respecto, en virtud de que tras una mujer (que estaba en primer lugar de la lista correspondiente), se encontraban dos hombres y luego dos mujeres. La Sala Superior al resolver clarifica el concepto de alternancia en tanto uno a uno y en secuencia, restituyendo, así, en su derecho político a participar en elecciones internas partidarias y ser postulada, posteriormente, en el ámbito representativo democrático.

- En este sentido es memorable el SUP-JDC-3049/2009, y su acumulado, el SUP-JDC-3048/2009, el TEPJF admitió competencia para conocer de dos clases de peticiones. En una de ellas, una diputada federal en funciones, Olga Luz Espinosa Morales, quien había solicitado licencia definitiva, pide al Tribunal obligue a la Cámara de Diputados que resuelva en forma definitiva una solicitud de licencia al cargo de representación del que es titular; a su vez, en la segunda petición, un diputado federal suplente precisa- 
mente en la fórmula de la legisladora Espinosa Morales, y quien, por tanto, no está en funciones, solicita al tribunal que revoque y ordene a la Mesa Directiva de la Cámara de Diputados o a la Comisión Permanente del Congreso de la Unión que le llamen para tomar protesta para asumir el cargo de diputado federal.

\section{Vuelta a la tuerca: una sentencia paliativo ¿con repercusiones a futuro?}

El 30 de noviembre de 2011, la Sala Superior del Tribunal Electoral del Poder Judicial de la Federación emitió resolución al juicio para la protección de los derechos políticos electorales identificados con el alfanumérico SUP-JDC-12624/2011 y acumulados, incoados por María Elena Chapa Hernández, María de las Nieves García Fernández, María Cruz García Sánchez, Refugio Esther Morales Pérez, Rocío Lourdes Reyes Willie, María Fernanda Rodríguez Calva, María Juana Soto Santana, Martha Angélica Tagle Martínez, María de los Ángeles Moreno Uriegas y Laura Cerna Lara, ${ }^{18}$ con la finalidad de impugnar el acuerdo CG327/2011, "Acuerdo del Consejo General del Instituto Federal Electoral por el que se indican los criterios aplicables para el registro de candidaturas a los distintos cargos de elección popular que presenten los partidos políticos y, en su caso, las coaliciones ante los Consejos del Instituto, para el proceso electoral federal 2011-2012".

La resolución se considera un hito en el cumplimiento de cuotas de género que, indefectiblemente lleva a la equidad entre los géneros. ${ }^{19}$

${ }_{18}$ En estricto sentido el proveído del magistrado instructor se enderezó a decretar la acumulación de los expedientes identificados con las claves SUP-JDC-12624/2011, SUPJDC-12625/2011, SUPJDC-2626/2011, SUP-JDC-12627/2011, SUP-JDC-12628/2011, SUP-JDC-12629/2011, SUP-JDC-12630/2011, SUP-JDC-12631/2011, SUP-JDC-12634/ 2011 y SUP-JDC-12635/2011.

19 Más allá de los diversos conceptos en torno a la equidad de género, afirmamos que el término sustantivo que soporta su contenido lo es el de proporcionalidad en tanto que en sí mismo predica la defensa de la igualdad entre hombres y mujeres en todo aquello que implica tanto el goce y ejercicio de derechos, en tanto situaciones sustantivas, como aquellas que se dirigen al acceso y uso de los bienes y servicios en el contexto del Estado constitucional y democrático. Así, el concepto de proporcionalidad en tanto un tertium comparationis supone abolir la discriminación entre ambos sexos y que no se privilegie al hombre en ningún aspecto de la vida social, tal como era frecuente hace algunas décadas en la mayoría de las sociedades occidentales. 
En estricto sentido los puntos nodales combatidos por las accionantes en tutela de protección de sus derechos políticos-electorales se enderezan en contra del décimo tercer punto del acuerdo de referencia específicamente en sus párrafos cuarto (íntegro) y la expresión "procurando", así como los párrafos tercero y quinto por lo que hace a los criterios aplicables para el registro de candidaturas a los distintos cargos de elección popular que presenten los partidos políticos y, en su caso, las coaliciones.

Expresado en términos de agravios, podríamos indicar que se ciñen las impugnaciones a los puntos elementos siguientes:

1) El exceso de reglamentación por parte del Consejo General en relación con el artículo 219 del Código Federal de Instituciones y Procedimientos Electorales, por lo que hace a la definición de la expresión "procesos democráticos".

2) La frase "procurando que la fórmula completa se integre por candidatos del mismo género" contenida en los párrafos tercero y quinto del punto de acuerdo decimotercero del acuerdo CG327/2011.

Por lo que hace al primer punto, y contraviniendo en todo el principio de legalidad contenido en los artículos 14 y 16 y el diverso de certeza jurídica contenida en el artículo 41 todos de la Constitución general de los Estados Unidos Mexicanos, el Consejo General al definir el concepto de "proceso democrático" y remitir, eventualmente, a los Estatutos de los partidos políticos para exceptuar de la cuota de género a las candidaturas de mayoría relativa, se excedió de la facultad reglamentaria que los artículos 3o. y 118 del Cofipe le reconocen, máxime

La equidad de género consiste en estandarizar las oportunidades existentes para repartirlas de manera justa entre ambos sexos. Los hombres y las mujeres deben contar con las mismas oportunidades de desarrollo. El Estado por lo tanto, tiene que garantizar que los recursos sean asignados de manera simétrica.

Una mujer no debe obtener menos que un hombre ante un mismo trabajo. Cualquier persona debe ganar lo propio de acuerdo a sus méritos y no puede ser favorecida en perjuicio del prójimo. Un hombre y una mujer deben recibir la misma remuneración ante un mismo trabajo que contemple idénticas obligaciones y responsabilidades.

Esta situación de equidad debe alcanzarse sin descuidar las características de género. Las mujeres, por ejemplo, tienen derecho a una extensa licencia por maternidad, mientras que la licencia por paternidad es más breve. En este caso, se atiende a las cuestiones biológicas y se realiza una discriminación positiva entre ambos sexos. 
cuando de forma tan osada exceptúa, también, a las "candidaturas que se realizaran de forma indirecta a través de una convención o asamblea en la que participe un número importante de delegados electos ex profeso por dicha militancia”.

Para los señores consejeros ¿qué es un número importante de delegados electos ex profeso?

Por lo que hace al punto dos, la Sala Superior, tal como lo expresaron las impugnantes, asumieron en toda su dimensión la ratio contenida en el párrafo segundo del artículo 219 que en forma alguna contiene una recomendación a los partidos políticos para observar la cuota, el imperativo normativo lo es en tanto obligación, tal cual es la intención de paliar el estado de desventaja e inclusividad de uno de los géneros, al caso el femenino, en la representación política.

Aunado a lo anterior, la meridianidad con la cual la sentencia trata la cuota de género respecto de su conformación en la posición de propietaria y suplente, está enderezada al $40 \%$ reservado, en la transitoriedad, a las mujeres. Esto es así, como un mecanismo para garantizar que no se dará la elusión electoral concretada en las elecciones de 2009, con las ya referidas líneas arriba "Juanitas".

Un punto a favor de la sentencia lo es la invocación a los instrumentos internacionales de derechos humanos en materia de igualdad de géneros y titularidad y ejercicio de derechos políticos electorales.

Finalmente vale mencionar los puntos resolutivos de la sentencia:

Se ordena al Consejo General expulsar el párrafo cuarto del Punto Décimo Tercero del Acuerdo;

Del mismo Punto modifica como se transcribe los párrafos tercero y quinto:

Esto es, en caso de que el partido político, elija a sus candidatos de mayoría relativa mediante un proceso de elección democrático observando y privilegiando lo previsto en sus estatutos respecto de la forma de elección, el partido político o coalición, en todo caso, deberá presentar como mínimo 120 y 26 candidatos propietarios de un mismo género, a Diputados y Senadores, respectivamente en términos de lo dispuesto por el primer párrafo del artículo 219 del Código Federal de Instituciones y Procedimientos Electorales.

Las listas de representación proporcional se integrarán por segmentos de cinco candidaturas. En cada uno de los segmentos de cada lista habrá dos candidaturas de género distinto, de manera alternada. En el caso de 
las candidaturas que conforman la cuota de género prevista en el artículo 220, párrafo primero, del Código Federal de Instituciones y Procedimientos Electorales (mínimo cuarenta por ciento del total), la fórmula completa (propietario y suplente) debe integrarse por candidatos del mismo género. Tratándose de la lista de candidatos a Senadores, los dos últimos lugares serán ocupados por un candidato de cada género.

\section{Bordando fino}

El 14 de diciembre del mismo 2011, el Consejo General del Instituto Federal Electoral en cumplimiento de la sentencia expuesta líneas arriba, emite el Acuerdo CG413/2011 y modificatorio del diverso CG327/2011, sólo en lo que hace a los párrafos 30., 4o. y 50., quedando como sigue:

Décimo tercero. De la totalidad de solicitudes de registro de candidaturas a Diputados y Senadores, tanto de mayoría relativa como de representación proporcional, que presenten los partidos políticos o coaliciones ante el Instituto Federal Electoral, en ningún caso incluirán más del sesenta por ciento de candidatos propietarios de un mismo género. Además, se verificará que los partidos políticos hayan observado los porcentajes de género establecidos en sus propios Estatutos.

Quedan exceptuadas de la regla de género señalada en el párrafo anterior, las candidaturas de mayoría relativa que sean resultado de un proceso de elección democrático.

Esto es, en caso de que el partido político elija a sus candidatos de mayoría relativa mediante un proceso de elección democrático, observando y privilegiando lo previsto en CG413/2011 sus Estatutos respecto de la forma de elección, el partido político o coalición, en todo caso, deberá presentar como mínimo 120 y 26 candidatos propietarios de un mismo género, a Diputados y Senadores, respectivamente en términos de lo dispuesto por el primer párrafo del artículo 219 del Código Federal de Instituciones y Procedimientos Electorales.

Las listas de representación proporcional se integrarán por segmentos de cinco candidaturas. En cada uno de los segmentos de cada lista habrá dos candidaturas de género distinto, de manera alternada. En el caso de las candidaturas que conforman la cuota de género prevista en el artículo 220, párrafo primero, del Código Federal de Instituciones y Procedimien- 
tos Electorales (mínimo cuarenta por ciento del total), la fórmula completa (propietario y suplente) debe integrarse por candidatos del mismo género. Tratándose de la lista de candidatos a Senadores, los dos últimos lugares serán ocupados por un candidato de cada género.

La secuela procesal no queda sólo en la emisión del Acuerdo antes indicado sino que, además, en noviembre del mismo año, el secretario general del Consejo platea ante la Sala Superior del Tribunal Electoral del Poder Judicial de la Federación un escrito de aclaración de sentencia en relación con los efectos de la sentencia del SUP-JDC-12624/2011 y acumulados, ${ }^{20}$ podemos decir, un tanto "premonitorio" respecto del eventual no cumplimiento de las cuotas conforme a los procedimientos establecidos en los Estatuto de cada uno de los partidos políticos, particularmente en lo que hace aquellos mecanismos de selección vía procesos democráticos de cara a la insuficiente participación y triunfo de mujeres para satisfacer la cuota, hic et $n u n c,{ }^{21}$ obligada de género.

Más aún, la aclaración se endereza a plantear tanto el supuesto de hacer nugatorios los derechos de sufragio pasivo de los varones militantes de los institutos políticos en aras del cumplimiento de las cuotas, así como lo atinente a aquellas candidaturas que ya habían sido materia de asignación y, en consecuencia, la eventual vulneración de derechos adquiridos.

El resultado del incidente era previsible, id. est., se declaró improcedente ciñendo los efectos de la sentencia a los puntos ya transcritos (definiens definium).

A la sazón hasta el momento en que se escribe el presente documento, se han interpuesto cuatro juicios para la protección de los derechos político electorales del ciudadano identificados con los alfanuméricos SUP-JDC-14855/2011 y acumulados (23 de diciembre de 2011), en contra del CG413/2011 mediante el cual el Consejo General del IFE cumplimenta la resolución recaída al multireferido SUP-JDC

20 Véase IFE, Ruta crítica de la cuota de género a nivel federal. Evolución jurisdiccional, México, marzo de 2012.

${ }_{21}$ Decimos que el efecto de la sentencia es hic et nunc, en razón que es a partir del planteamiento de su disconformidad que rige desde el momento en que es emitida y causa estado sólo para los casos a futuro, no puede, bajo ningún concepto tener efectos ex tunc, en virtud que en ningún resolutivo se retrotraen los efectos de la referida sentencia a casos anteriores y no podría toda vez que, tal como lo hizo el secretario general del Consejo General del IFE, se vulneran derechos adquiridos. 
12624/2011, desde luego, argumentando violación a su derecho a ser votados en los procesos de selección interna en mayoría relativa o postulados en los segmentos de representación proporcional, afectación al principio de autonomía de autoorganización partidaria, afectación a derechos adquiridos, inter alia. El medio de impugnación fue, obvio, desechado y se confirmó el Acuerdo sustitutorio.

No es el quid del presente documento narrar el iter de eventos que se han sucedido que van desde los escritos presentados por los partidos políticos ante el Consejo General del IFE, argumentando el eventual incumplimiento de las cuotas de género por ambos principios electorales en virtud de la insuficiencia de mujeres en las contiendas internas en mayoría relativa o a efecto de su inserción en las listas de representación proporcional.

En este sentido quizá resulta más ilustrativo el informe presentado por el presidente del Consejo General del Instituto Federal Electoral presentado ante el órgano máximo del ente administrativo electoral federal el 26 de marzo de 2012 y que causó por demás revuelo ante el incumplimiento de los partidos políticos respecto de la cuota de género y sus eventuales sanciones. ${ }^{22}$

El 28 de marzo, a un día del inicio formal de las campañas electorales, los institutos políticos, finalmente, cumplieron "voluntariamente" con la cuota obligatoria, así el PAN anunció que sustituyó a 44 hombres; el PRI y PVEM, a 54, y el PRD, PT y Movimiento Ciudadano, a 28.

Triste realidad: las cuotas vuelven a ser utilizadas para beneficio de los mismos, me explico, la sustitución que se verificó es elusiva de la cuota ya que quienes quedaron integrando fórmula guardan cualesquier vínculo de parentesco con quienes ya no son, a guisa de ejemplo: la hermana de la hasta ahora gobernadora de Yucatán, Guadalupe Ortega Pacheco subió a candidata a diputada federal en la 3a. Circunscripción y María del Carmen Ordaz, esposa de José Blanco ex alcalde de Progreso Blanco Pajón, bajó y su cónyuge ahora es la candidata a la diputación del 2o. distrito electoral federal. El procedimiento en todos los casos y entidades es el mismo. Do ut des y dicho en buen castellano palaciego "doy para que des", la mano visible del "jardín secreto de

${ }^{22}$ Informe que presenta el consejero presidente del Consejo General del Instituto Federal Electoral, respecto a la cuota de género prevista en los artículos 219 y 220 del Cofipe con relación al numeral 221 del mismo ordenamiento legal y al acuerdo del Consejo General CG413/2011, del 26 de marzo de 2012. 
las candidaturas", ${ }^{23}$ las "Juanitas" en el proceso 2012 han parido una nueva modalidad.

Como corolario de lo anterior el 18 de junio del presente año la Sala Superior del Tribunal Electoral del Poder Judicial de la Federación integró jurisprudencia en materia de cuotas de género: que establece que los partidos políticos deberán integrar, con personas del mismo género, sus fórmulas de candidatos a diputados y senadores por ambos principios.

Si bien la actividad de la Sala es por demás encomiable, también lo es que en materia de constitucionalidad existen límites a la eventual actividad de expansión de derechos fundamentales, más allá de la posición "garantista ferrajoliana" que sostienen ciertos magistrados del Tribunal Electoral federal, y esto es así dado que existe un imperativo constitucional que están obviando y es que el artículo 41, fracción I, párrafo tercero, determina a la letra que: "Las autoridades electorales solamente podrán intervenir en los asuntos internos de los partidos políticos en los términos que señalen esta Constitución y la ley”.

Como bien lo apunta José Alfonso da Silva, ${ }^{24}$ la interpretación en uno de los mecanismos de actualización informal de la Constitución que, indefectiblemente, requiere del diverso formal que es la reforma constitucional, así:

La interpretación, como tal, no puede cambiar la Constitución, por sí misma. La interpretación jurídica, en cualquiera de sus formas, es un modo de comprensión, que es una modalidad de conocimiento. "Comprender, advierte Cossío, es conocer algo en su ser cuando este ser es un ser sentido, e interpretar y comprender el objeto cultural ya creado. La interpretación es, así, un conocimiento cultural, lo que, en último análisis, significa que la interpretación es un problema de la teoría del conocimiento", aplicada a los bienes culturales, como el derecho. Esto quiere decir que la interpretación busca conocer el objeto de conocimiento, tal como se presenta, o sea, sin modificarlo. Vale decir, la interpretación (salvo la interpretación constructiva de que hablaremos enseguida), por sí no puede producir mutación constitucional. Lo que puede es mostrar que

${ }^{23}$ Dahlerup, Drude y Freidenvall, Lenita, Sistemas electorales de cuotas de género y su aplicación en Europa. Derechos de las mujeres e igualdad de género, Bruselas, Parlamento Europeo, 2008, pp. 2 y 17.

24 "Mutaciones constitucionales", Cuestiones Constitucionales, Revista Mexicana de Derecho Constitucional, núm. 1, julio-diciembre de 1999, p. 16. 
el objeto por conocer se transformó, bien porque la realidad a la que se refiere evolucionó y requiere que el objeto normativo se acomode a ella, si tiene elasticidad suficiente para ello, o porque palabras o expresiones normativas sufrieron cambios semánticos que exigen que su nuevo sentido sea explicitado por la interpretación.

Más aún, continúa el autor de referencia:

La construcción constitucional es una forma de interpretación fecunda en la medida que, partiendo de una comprensión sistemática de principios y normas constitucionales, construyen instituciones explícitamente no previstas. Como cualquier forma de construcción, también la construcción constitucional consiste en la reunión de varios elementos en una edificación unitaria. ${ }^{25}$

El quid de la cuestión es que, inopinadamente, existe una extralimitación en la labor tuitiva de la Sala, máxime cuando han extendido el porcentaje de cuota de género en la aplicación del principio electoral de mayoría relativa quebrantando, desde nuestra óptica, el principio de equidad. Estoy plenamente convencida que forzar al tránsito de cuota a equidad no está dando los resultados deseados, las cifras lo denotan categóricamente. Ello nuevamente me hace cuestionarme:

CUOTAS PARA QUÉ... CUOTAS PARA QUiÉN

\section{Conclusiones}

Primera. Existe una realidad que es insoslayable, los partidos políticos tratan a toda costa eludir las disposiciones que les obligan respetar el umbral de representatividad de las mujeres de diversa manera.

Segunda. En aras de la virulenta entre el PRI y el PAN aquél para recobrar lo perdido y éste para mantenerse en la Presidencia, se evidenciará una erosión en el cumplimiento de las cuotas de género, que se verá reflejado en el alza de los juicios para la protección de los derechos políticos de las ciudadanas.

25 Ibidem, p. 19. 
Tercera. Si bien existe una vocación para rendir eficaz la institucionalidad electoral, aún sigue pendiente el impulso a derechos/libertades como el de petición, manifestación y esencialmente asociación de la mujeres.

Quinta. Ha menester el reforzamiento de mecanismos de transparencia, rendición de cuentas y responsabilidades ante el incumplimiento tanto de las cuotas, como del $2 \%$ de financiamiento destinado a la capacitación y formación de liderazgo femenino.

Sexta. Si bien los partidos políticos eluden sus obligaciones de cuotas, equidad y paridad y ya han sido sometidos a eventuales mecanismos de fiscalización, también ha menester que las instituciones que apoyan el adelanto de las mujeres queden sometidas a una férrea auditoría respecto del uso y destino de los recursos destinados a las mujeres y su desarrollo político.

Séptima. El panorama no es halagüeño para las mujeres, aún hay mucho trecho por andar, sobre todo a nivel de jurisdicción electoral, sobre todo ante la veleidad judicial.

Octava. México ha transitado hacia un modelo normativo óptimo en materia de cuotas (salvo lo que hace a su reconocimiento constitucional), quizá en la frontera misma que otros Estados nacionales a la vanguardia, pero el problema no es de diseño, el verdadero problema radica en una cultura de la simulación y el fraude, de la negociación y las componendas. Mientras la situación se mantenga y las mujeres no sean beneficiarias directas del compromiso de género de hombres y mujeres que ejercen el poder, poco se logrará en materia de adelanto de las mujeres.

\section{Fuentes de consulta}

Antonopoulos, Rania, Estado, diferencia, diversidad: buscando un camino con mayor democracia e igualdad de género, en Democracia. Estado. Ciudadanía. Hacia un Estado de y para la Democracia en América Latina, Lima, PNUD, 2007.

Benitez Manaut, Raúl, "La crisis de seguridad en México", Nueva Sociedad, México, Fundación Friedrich Ebert, núm. 220, marzo-abril de 2009, http://nuso.org/upload/articulos/3601_1.pdf (3 de noviembre de 2010). 
Camacho, Carlos, "Propuesta de un Modelo de Comunicación Masiva para la construcción de ciudadanía en América Latina", Razón y Palabra, núm. 74, octubre-noviembre de 2003, http://razonypala bra.org. mx/anteriores/n35/ccamacho.html.

Cano, Gabriela, "Las feministas en campaña”, Debate Feminista, núm. 4, 1991.

Cifras consultadas en el sitio de GEPALL: Género y Partidos Políticos en América Latina, Banco Interamericano de Desarrollo, http:// www6.iadb.org/Research/Geppal/tabsdataParty.cfm?language=Span ish\& country $=$ MEX\&parties $=57 \&$ category $=1$ \&pagref $=1$.

Declaración Americana de los Derechos y Deberes del Hombre, Bogotá, 1948.

Diario Oficial de la Federación, 31 de diciembre de 1974.

Diario Oficial de la Federación, 13 de noviembre de 2007.

Diario Oficial de la Federación, 14 de enero de 2008.

Diario Oficial de la Federación, 7 de julio de 2011.

Diario Oficial de la Federación, 8 de septiembre de 2008.

Diario Oficial de la Federación, 14 de enero de 2001.

Diario Oficial de la Federación, 14 de enero de 2008.

Diario Oficial de la Federación, 21 de diciembre 2009.

Dietz, Mary G., El contexto es lo que cuenta: feminismo y teorías de la ciudadanía, Debate feminista, 2001.

Género y Democracia, México, IFE, 2011, http://genero.ife.org.mx/genero_partidos.html.

Gómez Maganda, Margarita, Mujer y política: La lucha por la igualdad en México, en de igual a igual, México, Segob-Programa Nacional de la Mujer-Coordinación General de la Comisión Nacional de la Mujer, 2000.

"Hacia la construcción de un Estado de ciudadanía", Seminario Internacional Estado, democracia y construcción de ciudadanía en América Latina, México, PNUD, Unión Europea, Colegio de México, Centro de Investigación y Docencia Económica, Fundación Este País, 2008, p. 3, http://www.gobernabilidaddemocratica-pnud.org/ archivos/1254759092Debates\%20Seminario\%20Democracia\%20AL. $p d f$.

Hernández, María del Pilar, "Avances de los derechos humanos de la mujer en México? Hacia una pedagogía de la igualdad en la diferencia”, Revista Latinoamericana de Derecho Social, núm. 10, enerojunio de 2010. 
- ——, "La participación de la mujer en el ámbito público: economía, administración y política”, Boletín Mexicano de Derecho Comparado, núm. 101, mayo-agosto de 2001.

Instituto Federal Electoral, Estudio muestral de participación ciudadana en las elecciones 2009, www.ife.org.mx.

Lagarde, Marcela, Género y Feminismo. Desarrollo Humano y Democracia, Madrid, Horas y Horas, 1997.

Levitsky, Steven y Wolfson, Leandro, "Del sindicalismo al clientelismo. La transformación de los vínculos partido-sindicatos en el peronismo, 1983-1999”, Desarrollo Económico, vol. 44, núm. 173, junio.

Mouffe, Chantal, Feminismo, ciudadanía y política democrática radical, Debate feminista, 2001.

Munck, Gerardo L., 2004, "La política democrática en América Latina, contribuciones de una perspectiva institucional", Política y Gobierno, núm. 2, II semestre.

Nuestra Democracia, México, Programa de Naciones Unidas para el Desarrollo, Secretaría General de Naciones Unidas-FCE, 2011.

O’Donnell, Guillermo, "Delegative Democracy", Journal of Democracy, núm. 1, enero de 1994.

Ríos Tovar, Marcela, "Género, Ciudadanía y Democracia”, en Democracia. Estado. Ciudadanía. Hacia un Estado de y para la Democracia en América Latina, Lima, PNUD, 2007.

Sánchez Olvera, Alma Rosa, "El feminismo en la construcción de la ciudadanía de las mujeres en México", Revista Itinerario de las Miradas, núm. 63, abril de 2006.

VASAK, Karel, Human Rights: A Thirty-Year Struggle: the Sustained Efforts to give Force of law to the Universal Declaration of Human Rights, París, UNESCO, Courier 30:11, United Nations Educational, Scientific and Cultural Organization, 1977.

Zaremberg, Gisela, Mujeres, votos y asistencia social en el México priista y la Argentina peronista, México, Flacso, 2009. 